\title{
Induction of gonadal sex reversal in adult gonochorist teleost by chemical treatment: an examination of the changing paradigm
}

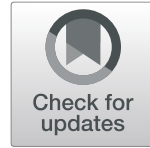

Maurice Eghosa Imiuwa(D)

\begin{abstract}
Background: Gonochorist teleosts are teleosts in which individuals develop either as males or as females, and are sexually stable thereafter throughout ontogeny. However, there is a labile period, defined as the time period prior to hatching through juvenile stage before sexual maturation (adulthood), during which gonadal sex differentiation can be influenced by environmental conditions, including exogenous chemical treatments. Usually, during this period, depending on the nature of chemical treatment, gonadal sex can be reversed from one phenotypic sex to another. A number of chemicals, ranging especially from sex steroids (natural and synthetic) to the more recent one, aromatase inhibitors, have been employed for the purpose of sex reversal in different gonochorist teleost species during the labile period. Thus, the labile period requirement for treatment application before adulthood in order to achieve gonadal sex reversal in gonochorist teleost is well founded. Interestingly, however, some degree of gonadal bipotentiality has recently been reported with mixed findings in adults of certain gonochorist teleost species upon treatment with exogenous chemicals, especially aromatase inhibitors. Consequently, it is now widely thought that gonochorist teleost species are amenable to chemical-induced gonadal sex reversal after sexual maturity.

Method: Here, all studies on chemical-induced gonadal sex reversal in adult gonochorist teleosts were reviewed. Results: Data strongly suggest that there are certain gonochorist teleost species in which adults may not be amenable to gonadal sex reversal through $17 \beta$-estradiol depletion by aromatase inhibitors and that the generalization of chemicalinduced gonadal sex reversal remains to be experimentally determined in adult gonochorist teleost.

Conclusion: It was concluded that further studies are required for clarification, considering, among others, that population-level effect models of these chemicals on wild fish populations are based on the understanding that environmental sex reversal occurs only during development and not after sexual maturity.
\end{abstract}

Keywords: Gonochorist teleost, Labile period, Adult gonadal sex reversal, Chemical treatment

\section{Background}

Early studies on reproductive behavior, while investigating hormonal role in the expression of secondary sex characters, revealed the possibility of experimental gonadal sex manipulation using sex steroids. Thereafter, gonadal sex manipulation in fish increasingly generated

Correspondence: maurice.eghosa@uniben.edu

Department of Animal and Environmental Biology, Faculty of Life Sciences, University of Benin, PMB 1154, Benin City, Edo State, Nigeria a lot of interest, due in part to their particularly intriguing unparalleled reproductive strategies and then applications in economically important species (Hunter \& Donaldson, 1983).

While there was a preponderance of studies on different fish species especially on the guppy, Lebistes recticulatus, and topminnow, Gambusia affinis (Berkowitz, 1938; Berkowitz, 1941; Eversole, 1939; Hopper, 1949; Turner, 1942), there were, however, a number of extensive studies on the Japanese medaka, Oryzias latipes. The first in the

\section{Springer Open}

(- The Author(s). 2020 Open Access This article is licensed under a Creative Commons Attribution 4.0 International License, which permits use, sharing, adaptation, distribution and reproduction in any medium or format, as long as you give appropriate credit to the original author(s) and the source, provide a link to the Creative Commons licence, and indicate if changes were made. The images or other third party material in this article are included in the article's Creative Commons licence, unless indicated otherwise in a credit line to the material. If material is not included in the article's Creative Commons licence and your intended use is not permitted by statutory regulation or exceeds the permitted use, you will need to obtain permission directly from the copyright holder. To view a copy of this licence, visit http://creativecommons.org/licenses/by/4.0/. 
series (Yamamoto, 1953) was a landmark which clearly demonstrated a complete and functional sex reversal in fish, and the fry prior to estrone treatment were genetically determined to be male as against the sex ratio criterion prevalent at the time. Further, it was observed that sex-reversed female (male genotype) were fertile and reproduced offspring on mating with normal male.

In female medaka, Yamamoto (1958) also observed a complete and functional sex reversal from female to male upon exposure to androgen following hatching for several months. Very clearly, Yamamoto (1959a) further evaluated the effect of estrone dosage level on the induction of sex reversal in both male and female medaka. He observed that the induction of sex reversal increased with dose. On the period of exogenous sex hormone application, Yamamoto (1959b) revealed with medaka that continuous treatment before the time of gonadal sex differentiation, through the stage of final differentiation, is sufficient to induce complete gonadal sex reversal. Interestingly, at low dosage level, Yamamoto and Matsuda (1963), in addition to some male-to-female sex reversal in estrogenized medaka, observed some intersex gonads, and the result further suggested optimal dose requirement for complete sex reversal.

On the subject, it became possible from available data to conclude and establish as criteria that hormone administration must cover the time prior to, and passing through, the stage of gonadal sex differentiation otherwise known as labile or window period in sufficient dose to induce complete and functional sex reversal in gonochorist teleost (Yamamoto, 1959b; Yamamoto \& Kajishima, 1968). Additionally, the criteria have been further demonstrated comprehensively in different gonochorist teleost species with sex steroid treatment. Thus, the requirement of exogenous chemical treatments only during the labile period, before sexual maturity, to induce complete gonadal sex reversal in gonochorist teleost is well founded (Nakamura et al., 2003; Pandian \& Kirankumar, 2003; Pandian \& Sheela, 1995; Piferrer, 2001; Shen et al., 2013).

Interestingly, however, some degree of gonadal sex reversal in adults of certain gonochorist teleost species upon chemical treatment has been recently demonstrated with mixed findings (Göppert et al., 2016; Sun et al., 2014; Takatsu et al., 2013). Consequently, gonochorist teleost species are now generally thought to be amenable to gonadal sex reversal with chemical treatment after sexual maturity (Baroiller \& D'Cotta, 2016; Rosenfeld et al., 2017; Sun et al., 2014). Nevertheless, not much is known about how these recent findings, individually and as a whole, compare with the longstanding understanding of the labile period requirement for gonadal sex reversal in gonochorist teleost. Here, for the first time, all studies on the induction of gonadal sex reversal in adult gonochorist teleosts by chemical treatments are reviewed. This, very clearly, is of critical importance as the environment is replete with the same endocrine-active chemicals (Sun et al., 2007), and population-level effect models of environmental sex reversal are essentially predicated on the understanding that gonadal sex reversal occurs only during development and not in adult fish (Cotton \& Wedekind, 2009; Hurley et al., 2004).

\section{Gonochorist teleosts}

These are teleost species in which individuals develop either as males or as females, and are stable thereafter throughout life (Patino, 1997). The gonadal developmental pathway usually taken to achieve this can be direct or indirect (Sandra \& Norma, 2010). However, what makes this group of teleost fish ongenetically different is that once gonadal sex is established, it remains so throughout life as against hermaphroditism (which simultaneously or sequentially have both female and male gonads) and unisexuality (all female individuals) (Baroiller \& D'Cotta, 2016).

According to Yamamoto (1969), there are two broad categories of gonochorist teleosts depending on the gonadal developmental pathway taken: they are the differentiated and the undifferentiated gonochorist teleosts. In the differentiated gonochorist teleost, gonadal differentiation proceeds from an indifferent gonad directly into either male or female gonads, whereas in the undifferentiated gonochorist teleost, all individuals initially develop only an ovary-type gonad, and subsequently, about half of the population develop testis upon apoptotic oocyte degeneration, while the other half develop as females (Sandra \& Norma, 2010). This developmental pathway taken by undifferentiated gonochorist, such as zebrafish, has also been described as non-functional protogynic hermaphroditism (Maack \& Segner, 2003) and juvenile hermaphroditism (Sandra \& Norma, 2010) because the ovary respectively contains only oocytes of the primary growth stage but not cortical alveolar or vitellogenic oocyte stage, and gonadal differentiation proceeds through a transient period of intersexuality before committing to either ovarian or testicular differentiation. Additionally, some gonochorist species have been described in which juveniles, initially with bipotential intersexual gonads, develop into males or females directly (Devlin \& Nagahama, 2002; Sandra \& Norma, 2010).

In both differentiated and undifferentiated gonochorist teleosts, gonadal differentiation usually goes through a species-specific labile or window period, during which they are amenable to gonadal sex reversal regardless of genetic sex (Pandian \& Kirankumar, 2003). The labile period typically occurs, however, during the time period between the undifferentiated gonad and terminal 
gonadal differentiation (Shen et al., 2013). Further, it is well founded that during the labile period, gonochorist teleost species retain gonadal bipotentiality and thereafter commit irreversibly to testicular or ovarian differentiation (Pandian \& Kirankumar, 2003; Piferrer, 2001; Shen et al., 2013).

\section{Labile period of gonadal differentiation in gonochorist teleosts}

The labile period of gonadal differentiation in gonochorist teleost has been defined as the period of time covering one or more life stages, when the sexually undifferentiated or differentiating gonad is responsive and amenable to the desired high percentage of sex reversal on exposure to an optimal dose of sex-inducing substance (Mathieu-Denoncourt et al., 2015; Shen et al., 2013). Gonadal histological studies of a number of gonochorist teleost species have long established that depending on the inception and duration of gonadal differentiation, the labile period can be grouped into two broad life stages, which are the immediate post-hatching and the late juvenile stages (Piferrer, 2001; Yamazaki, 1976). The immediate post-hatching stage labile period, which is the case for most gonochorist teleost species, corresponds to 10-40 days following hatching (or just before hatching in some cases) (Pandian \& Kirankumar, 2003), whereas the late juvenile stage labile period corresponds to 150-500 days, covering the beginning of gonadal sex differentiation and its duration into late juvenile (Pandian \& Sheela, 1995). Further, this has been extensively described in gonochorist teleosts with different chemical treatments (Devlin and Nagahama, 2002).

A number of exogenous chemicals have been used for gonadal sex reversal in fish, chief among which are natural and synthetic sex steroids (reviewed by Devlin and Nagahama, 2002; Piferrer, 2001). Other chemicals such as neuropeptides (Kramer \& Imbriano, 1997) and, more recently, aromatase inhibitors (Afonso et al., 2000; Piferrer et al., 1994) and other steroidogenic enzyme inhibitors such as trilostane, metopirone, and glycyrrhetinic acid (Shi et al., 2017) have also been reported. Further, these sex-inducing chemicals have been shown to result in varying degrees of gonadal sex reversal in gonochorist teleost fishes (Pandian \& Kirankumar, 2003), and it is not known whether there is also variation in the molecular mechanism regulating the maintenance of sexual phenotype in adults of these species.

\section{Maintenance of sexual phenotype in adult gonochorist teleost}

It is generally thought that sexual development, including maintenance of sexual phenotype, downstream of sex determination is conserved among phyla unlike sex determination (Kobayashi \& Nagahama, 2009). However, mounting evidence shows that such downstream sexual developmental program may not be conserved in gonochorist teleosts (Böhne et al., 2013). In female mammals, or at least in mice, genetic analyses show that forkhead box L2 gene (foxl2) and estrogen are required for the maintenance of femaleness throughout adult life (Uhlenhaut et al., 2009) and are considered the most conserved ovary-maintenance factors in vertebrates (Heule, Salzburger, \& Böhne, 2014). The role of foxl2 appears to be estrogen-mediated, through its transcriptional activation of Cyp19a1a (ovarian aromatase), an enzyme responsible for the biosynthesis of estrogen (Wang et al., 2007).

Expectedly, in female gonochorist teleosts, though the cascade of molecular regulation responsible for the maintenance of ovarian phenotype is far from understood, estrogen appears to oversee this process (Paul-Prasanth et al., 2013; Takatsu et al., 2013). Consistent with this, as oocyte-deficient ovary usually fails to maintain the expression of cyp19a1a (Rodriguez-Mari et al., 2010), an oocytederived signal has been demonstrated to be particularly prominent in the maintenance of female sexual phenotype throughout adult life in zebrafish, in which oocyte ablation resulted in female to male gonadal sex reversal (Dranow et al., 2013a). However, it is increasingly becoming probable that this pathway, requiring estrogen for the maintenance of female sexual phenotype, may not be conserved in adult gonochorist teleost. For example, in the cichlids, Ophthalmotilapia ventralis, there is a shift in the expression of cy19a1a from ovary-specific to ovaries and testes, while in Astatotilapia burtoni, the main site of cyp19a1b (the brain isoform of aromatase in teloests) synthesis is the testis and not the brain (Heule et al., 2014). Notably, this deviation does not explain the general assumption that ovary-specific upregulation of estrogen expression is required to maintain female sexual phenotype in adult gonochorist teleosts.

Conversely, in male mammals, the Sry-related high mobility group box 9 gene (sox9), which has been considered as one of the most conserved testicular factors in sexual development in vertebrates, is also thought to be the female's cyp19a1a counterpart (Uhlenhaut et al., 2009; Valenzuela et al., 2013). In gonochorist teleosts, sox9 appears to have a role concerned with both initiation of testicular differentiation in some species (Raghuveer \& Senthilkumaran, 2010) and testicular development downstream of differentiation in other species (Chiang et al. 2001; Kobayashi \& Nagahama, 2009; Nakamoto et al., 2005). Additionally, expression of ovary type sox9 has also been reported in some gonochorist teleosts (Kobayashi \& Nagahama, 2009). Thus, the role of sox9 in fish is more flexible than that seen in mammals. Importantly, however, while the genetic network responsible for the maintenance of male sexual phenotype in adult gonochorist teleost remains to be 
elucidated, the general assumption is that it requires the downregulation of estrogen through the suppression of folx 2 and cyp19a1a to prevent the transdifferentiation of terminally differentiated testis to ovary (Uhlenhaut et al., 2009). Nonetheless, the recent demonstration that estrogen is highly expressed in both ovaries and testes of adult $A$. burtoni and $O$. ventralis implies that the pathway responsible for the maintenance of terminally differentiated testes may not be conserved in adult gonochorist teleost (Böhne et al., 2013). Put together, this strongly suggests that there may be variation in the physiological response, including gonadal sex reversal, to chemicals which have potential to interfere with sex steroid in adult gonochorist teleosts, and the generalization of such responses may be difficult.

\section{Chemical-induced sex reversal in adult gonochorist teleost: recent findings}

Recently, it has been observed with mixed findings, some degree of gonadal bipotentiality in adults of certain gonochorist teleost species upon exposure to exogenous chemicals, especially aromatase inhibitors (AI) (Table 1). In breeding female medaka, O. latipes, exposure to AI affected oocyte development (Sun et al., 2007). Exposed fish had small oocytes that lacked dense-staining material compared to the control which had oocytes at various stages of maturation. There was, however, no intersex or sex reversal effect. However, in breeding female Nile tilapia, O. niloticus (5 months old), and O. latipes (1 year old), gonadal transdifferentiation was induced through $17 \beta$-estradiol depletion by AI (Paul-Prasanth et al., 2013). Genetic female $O$. niloticus feed diet mixed with AI developed male sexual behavior, and $50 \%$ of AItreated group revealed complete and functional sex reversal, with progenies upon insemination of eggs from normal females. In O. latipes, $20 \%$ of AI-treated (waterborne) genetic female fish had complete and functional sex reversal. They were also demonstrated to be fertilization-competent with eggs from normal females. Further, marked development of secondary sexual character was obvious, revealed by the degeneration of

Table 1 Recent findings on gonadal sex reversal in adult gonochorist teleost

\begin{tabular}{|c|c|c|c|c|c|}
\hline Fish & Age & Treatment & $\begin{array}{l}\text { Treatment duration } \\
\text { (days) }\end{array}$ & $\begin{array}{l}\text { Observation (\% complete } \\
\text { and functional sex reversal) }\end{array}$ & References \\
\hline \multirow[t]{11}{*}{ Oreochromis niloticus (XY) } & \multirow[t]{7}{*}{30 dph* } & $17 \beta-E s t r a d i o l ~(E 2)$ & 60 & 8.3 & \multirow[t]{11}{*}{ Shi et al. (2017) } \\
\hline & & Trilostane (TR) & & 0.0 & \\
\hline & & Metopirone (MN) & & 0.0 & \\
\hline & & Glycyrrhetinic acid (GA) & & 0.0 & \\
\hline & & $\mathrm{TR}+\mathrm{E} 2$ & & 88.3 & \\
\hline & & $M N+E 2$ & & 60.0 & \\
\hline & & $\mathrm{GA}+\mathrm{E} 2$ & & 46.7 & \\
\hline & \multirow[t]{4}{*}{$60 \mathrm{dph}$} & $\mathrm{TR}+\mathrm{E} 2$ & & 3.3 & \\
\hline & & E2 & & 0.0 & \\
\hline & & $M N+E 2$ & & 0.0 & \\
\hline & & $\begin{array}{l}\mathrm{GA}+\mathrm{E} 2(150 \mu \mathrm{g} / \mathrm{g} \\
\text { diet })\end{array}$ & & 0.0 & \\
\hline $\begin{array}{l}\text { Astatotilapia burtoni } \\
\text { (female) }\end{array}$ & $\begin{array}{l}\text { Sexually } \\
\text { mature }\end{array}$ & $\begin{array}{l}\text { Fadrozole }(200 \mu \mathrm{g} / \mathrm{g} \\
\text { diet) }\end{array}$ & 168 & 0.0 & Göppert et al. (2016) \\
\hline \multirow[t]{4}{*}{ Oreochromis niloticus $(X X)$} & 15 dph & \multirow{4}{*}{$\begin{array}{l}\text { Fadrozole }(200 \mu \mathrm{g} / \mathrm{g} \\
\text { diet) }\end{array}$} & 15 & 100 & \multirow[t]{4}{*}{ Sun et al. (2014) } \\
\hline & 30 dph & & 30 & 0.0 & \\
\hline & 60 dph & & $30 / 60$ & 0.0 & \\
\hline & 90 dph & & $30 / 60 / 90$ & 0.0 & \\
\hline Oryzias latipes (female) & 5 months & Exemestane $(100 \mu \mathrm{g} / \mathrm{L})$ & $\sim 60$ & 20 & \multirow{2}{*}{$\begin{array}{l}\text { Paul-Prasanth et al. } \\
\text { (2013) }\end{array}$} \\
\hline Oreochromis niloticus (XX) & 1 year & $\begin{array}{l}\text { Fadrozole }(200 \mu \mathrm{g} / \mathrm{g} \\
\text { diet) }\end{array}$ & $\sim 180$ & 50 & \\
\hline Danio rerio (female) & $\begin{array}{l}\text { Sexually } \\
\text { mature }\end{array}$ & $\begin{array}{l}\text { Fadrozole }(0.2 \text { mg/g } \\
\text { diet) }\end{array}$ & $\sim 150$ & $\dagger$ & Takatsu et al.(2013) \\
\hline Oryzias latipes (female) & Breeding & 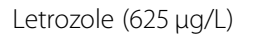 & 21 & 0.0 & Sun et al. (2007) \\
\hline
\end{tabular}

*Days post-hatching

tThough ovaries were observed to have completely retracted and testicular tissue developed $(n=9)$, it was however not clear the number tested for fertilization competence 
urogenital papillae and development of male-specific anal papillae in O. latipes.

In adult female zebrafish, D. rerio, $100 \%(n=9)$ ovarian transdifferentiation was also observed upon AI treatment (Takatsu et al., 2013). All AI-treated fish first developed testis-like tissue, containing cyst filled with spermatozoa-like cells following ovary retraction. The sperm, however, was not fertilization-competent until 2 months after treatment was discontinued. Further, there was no observable effect on sexual behavior and secondary sex characters. Contrary to the findings of PaulPrasanth et al. (2013) in breeding female O. niloticus, Sun et al. (2014) observed in AI-treated female O. niloticus (15 to $90 \mathrm{dph}$ ) a varying degree of treatmentinduced effects on the gonads. In this study, which has been described as complete and functional sex reversal (Baroiller \& D'Cotta, 2016; Shi et al., 2017), only 15 dph fish had complete and functional sex reversal, while others $(30,60$, and $90 \mathrm{dph})$ were either unaffected (purely ovarian tissues) or had ovotestes even with 90 days treatment $(90 \mathrm{dph})$. Further, it is worth noting that the complete and functional sex reversal reported (15 dph) was observed before the first morphological sign of ovarian histogenesis $(20 \mathrm{dph})$ in this species (Kobayashi et al., 2008).

Interestingly, in the East African cichlid, Astatotilapia burtoni, AI-treated sexually mature females had no sex reversal of any sort (complete or partial) as morphological and histological examination revealed only oocytes and not testicular tissues in the gonads of all AI-treated fish analyzed (Göppert et al., 2016). There was also no significant difference in serum 17ß-estradiol (E2) level and transcripts of ovary-specific genes in the AI-treated and control groups. However, AI-treated females had male-specific coloration, and treatment-impacted head and fin (dorsal and anal) morphology. Furthermore, in adult male (XY) O. niloticus, Shi et al. (2017) inactivated $3 \beta$-hydroxysteroid dehydrogenase (3ß-HSD), aldosterone synthase (cyp11b2), and $11 \beta$-hydroxysteroid dehydrogenase $(11 \beta-H S D)$ which are required for androgen biosynthesis, and administered $17 \beta$-estradiol (E2). They observed that treatment with $17 \beta$ estradiol (E2), trilosane (TR) (3ß-HSD inhibitor), metopirone (MN) (cyp11b2 inhibitor), and glycyrrhetinic acid (GA) (11ß-HSD inhibitor) applied alone or in combination with E2 from 30 dph resulted only in $8.3 \%$ gonadal sex reversal with E2 and 0.0\% sex reversal with the steroidogenic enzyme inhibitors. Additionally, with simultaneous application of the enzyme inhibitors and E2, there was $88.3 \%$ (TR + E2), 60.0\% (MN + E2), and 46.7\% (GA + E2) gonadal sex reversal. Expectedly, when treatment (E2 + enzymes inhibitors) was applied from $60 \mathrm{dph}$, only TR + E2 resulted in $3.3 \%$ gonadal sex reversal while others $(\mathrm{MN}+\mathrm{E} 2$ and $\mathrm{TR}+$ E2) were not affected, clearly indicative of effects of terminal differentiation with time.
Notably, there is an obvious, perhaps species-specific, variation in the effects of chemical treatments on gonadal sex in adult gonochorist teleost. The test chemicals, fadrozole, letrozole, and exemestane, act by inhibiting the enzyme, aromatase, that is responsible for the biosynthesis of estrogen, which is key to ovarian development (Guiguen et al., 2010; Kobayashi \& Nagahama, 2009), and has also been thought to oversee the maintenance of sexual phenotype in adult female fish (Dranow et al., 2013b; Rodriguez-Mari et al., 2010). Exemestane is a type I AI, while fadrozole and letrozole are type II AI. Type I AI are steroidal and inhibit aromatase by irreversibly binding the substrate-binding site of the enzyme, while type II AI are non-steroidal and bind reversibly to the enzyme (Leonard et al., 2014; López et al., 2014; Sun et al., 2007). It is important to point out that while fadrozole resulted in 50\% gonadal sex reversal in adult female $O$. niloticus (as the highest overall), it had no gonadal sex reversal effects, but only morphological and behavioral effects in adult female $A$. burtoni. This further suggests that estrogen may not be required to prevent the transdifferentiation of ovary to testis in adults of this species in which estrogen has been reported to be highly expressed in both ovary and testis (Böhne et al., 2013). Thus, generalizing the possibility of gonadal sex reversal in adult gonochorist teleost by chemical treatments from studies comprising only Beloniformes, Perciformes, and Cypriniformes orders of teleosts is far from certain in gonochorist teleost, which is a highly reproductively heterogeneous group (Avise and Mank, 2009).

\section{Conclusion}

Overall, these data clearly suggest that the molecular mechanism responsible for the maintenance of gonadal sex may not be conserved in adult gonochorist teleost. This, of course, is not without some environmental implications. For instance, inhibitors of key steroidogenic enzymes, including aromatase, have wide industrial and pharmaceutical applications and are increasingly becoming a class of emerging environmental contaminants of serious concern. With the burgeoning number of anthropogenic chemicals that are ubiquitously detected in the environment, and their implication in endocrinerelated adverse reproductive and developmental effects on wildlife, especially on fishes, population-level effect assessment, for pertinent integrative management approach, is increasingly becoming the focus. Consequently, different population-level effect models are being developed since response metrics from laboratory exposure are difficult to apply directly to wild populations. However, for sex reversal in fish, population-level effect models require clear cut delineation of the time of occurrence of environmental sex reversal, and this is 
currently based on the understanding that environmental sex reversal is only possible during development, within the labile period, and not in adult fish. Therefore, it has now become necessary to urgently understand in wild gonochorist teleost fish populations exposed to endocrine disruptive chemicals (EDCs) whether environmental or gonadal sex reversal (and not intersex) is only limited to juvenile stage or is possible throughout life even after sexual maturity. Thus, the generalization of the possibility of gonadal sex reversal in adult gonochorist teleost with chemical treatment requires further studies with different gonochorist teleost species for clarification.

\section{Abbreviations}

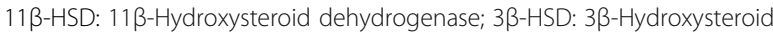
dehydrogenase; Al: Aromatase inhibitors; Cyp1 1b2: Aldosterone synthase; Cyp19a1a: Ovarian aromatase; Cyp19a1b: B-copy of Cyp19a1; dph: Days posthatching; E2: 17ß-Estradiol; Foxl2: Forkhead box L2 gene; GA: Glycyrrhetinic acid; MN: Metopirone; Sox9: Sry-related high mobility group box 9 gene; TR: Trilosane

\section{Acknowledgements}

The author would like to thank the Molecular and Reproductive Toxicology Research Group of the Department of Zoology, University of Ibadan, Nigeria.

\section{Author's contributions}

MEl has sole contribution for this article. The author read and approved the final manuscript.

\section{Funding}

There was no external funding for this research.

\section{Availability of data and materials \\ Not applicable}

Ethics approval and consent to participate

Not applicable

\section{Consent for publication}

Not applicable

\section{Competing interests}

The author declares that there are no competing interests.

Received: 5 September 2019 Accepted: 4 May 2020

Published online: 24 May 2020

\section{References}

Afonso, L. O. B., Iwama, G. K., Smith, J., \& Donaldson, E. M. (2000). Effects of the aromatase inhibitor Fadrozole on reproductive steroids and spermiation in male coho salmon (Oncorhynchus kisutch) during sexual maturation. Aquaculture, 188, 175-187.

Avise, C., \& Mank, J. E. (2009). Evolutionary perspectives on hermaphroditism in fishes. Sexual Development, 3, 152-163.

Baroiller, J., \& D'Cotta, H. (2016). The reversible sex of gonochoristic fish: Insights and consequences. Sexual Development, 10, 242-266.

Berkowitz, P. (1938). The effect of oestrogenic substances in Lebbtes reticulatus (Guppy). Anatomical Record, 71, 161-175.

Berkowitz, P. (1941). The effect of oestrogenic substances in the fish (Lebistes reticulatus). Journal of Experimental Zoology, 87, 233-243.

Böhne, A., Heule, C., Boileau, N., \& Salzburger, W. (2013). Expression and sequence evolution of aromatase cyp19a1 and other sexual development genes in East African cichlid fishes. Molecular Biology and Evolution, 30, 2268.

Chiang, E. F. L., Pai, C., Wyatt, M., Yan, Y., Postlethwait, J., \& Chung, B. (2001). Two Sox9 genes on duplicated zebrafish chromosomes: Expression of similar transcription activators in distinct sites. Developmental Biology, 231, 149-163.
Cotton, S., \& Wedekind, C. (2009). Population consequences of environmental sex reversal. Conservation Biology, 23(1), 196-206. https://doi.org/10.1111/j.15231739.2008.01053.

Devlin, R. H., \& Nagahama, Y. (2002). Sex determination and sex differentiation in fish: An overview of genetic, physiological, and environmental influences. Aquaculture, 208, 191-364

Dranow, D. B., Tucker, R. P., \& Draper, B. W. (2013a). Germ cells are required to maintain a stable sexual phenotype in adult zebrafish. Developmental Biology, $376,43-50$

Dranow, D. B., Tucker, R. P., \& Draper, B. W. (2013b). Germ cells are required to maintain a stable sexual phenotype in adult zebrafish. Developmental Biology, $376,43-50$

Eversole, W. J. (1939). The effects of androgens upon the fish (Lebistes reticulatus). Endocrinology, 25, 328-330.

Göppert, C., Harris, R. M., Theis, A., Boila, A., Hohl, S., Rüegg, A., \& Böhne, A. (2016). Inhibition of aromatase induces partial sex change in a cichlid fish: Distinct functions for sex steroids in brains and gonads. Sexual Development, 10, 97-110.

Heule, C., Salzburger, W., \& Böhne, A. (2014). Genetics of sexual development: An evolutionary playground for fish. Genetics, 196, 579-591.

Hopper, A. F. (1949). The effect of ethynyl testosterone on the intact and regenerating anal fins of normal and castrated females and normal males of Lebistes reticulatus. Journal of Experimental Zoology, 111, 393-414.

Hunter, G. A. \& Donaldson, E. M. (1983). Hormonal sex control and its application to fish culture. In W.S. Hoar, \& D. J. Randall, (Eds), Fish Physiology (pp223- 303). NY: Academic Press.

Hurley, M. A., Matthiessen, P., \& Pickering, A. D. (2004). A model for environmental sex reversal in fish. Journal of Theoretical Biology, 227, 159-165.

Kobayashi, T., Kajiura-Kobayashi, H., Guan, G., \& Nagahama, Y. (2008). Sexual dimorphic expression of DMRT1 and Sox9a during gonadal differentiation and hormone-induced sex reversal in the teleost fish Nile tilapia (Oreochromis niloticus). Developmental Dynamics, 237, 297-306.

Kobayashi, T., \& Nagahama, Y. (2009). Molecular aspects of gonadal differentiation in a teleost fish, the Nile tilapia. Sexual Development, 3, 108-117.

Kramer, C. R., \& Imbriano, M. A. (1997). Neuropeptide Y (NPY) induces gonad reversal in the protogynous blue head wrasse, Thalassoma bifasciatum. Journal of Experimental Zoology, 279, 133-144.

Leonard, J. A.r Cope, W. G., Barnhart, M. C., \& Bringolf, R. B. (2014). Metabolomic, behavioral, and reproductive effects of the aromatase inhibitor fadrozole hydrochloride on the unionid mussel. Lampsilis fasciola. General and Comparative Endocrinology., 206, 213-226.

López, J. J. B., Velez, J. C. Q., Alfonso, H. O., Barreiro-Sanchez, F., \& Angel, M. O. (2014). Effectiveness of the aromatase (P450 Arom) inhibitors Letrozole and Exemestane for masculinization of red tilapia (Oreochromis spp) Revista Colombiana de Ciencias Pecuarias, 27:47-53

Maack, G., \& Segner, H. (2003). Morphological development of the gonads in zebrafish. Journal of Fish Physiology, 62, 895-906.

Mathieu-Denoncourt, J., Wallace, S. J., Solla, S. R. D., \& Langlois, V. S. (2015), Plasticizer endocrine disruption: Highlighting developmental and reproductive effects in mammals and non-mammalian aquatic species. General and Comparative Endocrinology, 219, 74-88.

Nakamoto, M., Suzuki, A., Matsuda, M., Nagahama, Y., \& Shibata, N. (2005). Testicular type Sox9 is not involved in sex determination but might be in the development of testicular structures in the medaka, Oryzias latipes. Biochemical and Biophysical Research Communications, 333, 729-736.

Nakamura, M., Bhandari, R. K., \& Higa, M. (2003). The role estrogens play in sex differentiation and sex changes of fish. Fish Physiology and Biochemistry, 28, $113-117$.

Pandian, T. J., \& Kirankumar, S. (2003). Recent advances in hormonal induction of sex-reversal in fish. Journal of Applied Aquaculture, 13, 205-230.

Pandian, T. J., \& Sheela, S. G. (1995). Hormonal induction of sex reversal in fish. Aquaculture, 138, I-22.

Patino, R. (1997). Manipulations of the reproductive system of fishes by means of exogenous chemicals. The Progressive Fish-Culturist, 59, 118-128.

Paul-Prasanth, B., Bhandari, R. K., Kobayashi, T., Horiguchi, R., Kobayashi, Y., Nakamoto, M.,... Nagahama, Y. (2013). Estrogen oversees the maintenance of the female genetic program in terminally differentiated gonochorists. Scientific Reports, 3:2862 /DOI: 10.1038.

Piferrer, F. (2001). Endocrine sex control strategies for the feminization of teleost fish. Aquaculture, 197, 229-281.

Piferrer, F., Zanuy, S., Carrillo, M., Solar, I. I., Devlin, R. H., \& Donaldson, E. M. (1994). Brief treatment with an aromatase inhibitor during sex differentiation causes 
chromosomally female salmon to develop as normal, functional males. Journal of Experimental Zoology, 270, 255-262.

Raghuveer, K., \& Senthilkumaran, B. (2010). Isolation of sox9 duplicates in catfish: Localization, differential expression pattern during gonadal development and recrudescence, and hCG-induced up-regulation of sox9 in testicular slices. Reproduction, 140, 477-487.

Rodriguez-Mari, A., Canestro, C., Bremiller, R. A., Nguyen-Johnson, A., Asakawa, K. Kawakami, K., \& Postlethwait, J. H. (2010). Sex reversal in zebrafish fancl mutants is caused by Tp53 mediated germ cell apoptosis. PLoS Genetics, 6, e1001034.

Rosenfeld, C. S., Denslow, N. D., Orlando, E. F., Gutierrez-Villagomez, J. M., \& Trudeau, V. L. (2017). Neuroendocrine disruption of organizational and activational hormone programming in poikilothermic vertebrates. Journal of Toxicology and Environmental Health, Part B, 20, 276-304.

Sandra, G. \& Norma, M. (2010). Sexual determination and differentiation in teleost fish. Reviews in Fish Biology and Fisheries, 20, 101-121.

Shen, Z., Fan, Q., Yang, W., Zhang, Y., Hu, P., \& Xie, C. (2013). Effects of nonsteroidal aromatase inhibitor letrozole on sex inversion and spermatogenesis in yellow catfish Pelteobagrus fulvidraco. Biological Bulletin, 225, 18-23.

Shi, H., Gao, T., Liu, Z., Sun, L., Jiang, X., Chen, L., \& Wang, D. (2017). Blockage of androgen andadministration of estrogen induce transdifferentiation of testis into ovary. Journal of Endocrinology, 233, 65-80.

Sun, L., Zha, J., Philip, A., Spear, P. A., \& Wang, Z. (2007). Toxicity of the aromatase inhibitor letrozole to Japanese medaka (Oryzias latipes) eggs, larvae and breeding adults. Comparative Biochemistry and Physiology, Part C, 145, 533-541.

Sun, L. N., Jiang, X. L., Xie, Q. P., Yuan, J., Huang, B. F., Tao, W. J., ... Wang, D. S. (2014). Transdifferentiation of differentiated ovary into functional testis by long-term treatment of aromatase inhibitor in Nile tilapia. Endocrinology, 155, $1476-1488$

Takatsu, K., Miyaoku, K., Roy, S. R., Murono, Y., Sago, T., Itagaki, H.,... Tokumoto, T. (2013). Induction of female-to-male sex change in adult zebrafish by aromatase inhibitor treatment. Scientific Reports, 3: 3400/ DOI: https://doi.org/ 10.1038/srep03400

Turner, C. L. (1942). Morphogenesis of the gonopodial suspensorium in Gambusia afinis and the induction of male suspensorial characters in the female by androgenic hormone. Journal of Experimental Zoology, 91, 167-193.

Uhlenhaut, N. H., Jakob, S., Anlag, K., Eisenberger, T., Sekido, R., Kress, J., ... Treier, M. (2009). Somatic sex reprogramming of adult ovaries to testes by FOXL2 ablation. Cell, 139, 1130-1142.

Valenzuela, N., Neuwald, J. L., \& Literman, R. (2013). Transcriptional evolution underlying vertebrate sexual development. Developmental Dynamics., 242, 307-319.

Wang, D., Kobayashi, T., Zhou, L., Paul-Prasanth, B., Jiri, S., Sakai, F., \& Nagahama, Y. (2007). Foxl2 up-regulates aromatase gene transcription in a female-specific manner by binding to the promoter as well as interacting with Ad4 binding protein/steroidogenic factor 1. Molecular Endocrinology, 21, 712-725.

Yamamoto, T. (1953). Artificially induced sex reversal in genotypic males of the medaka (Oryzias latipes). Journal of Experimental Zoology, 123, 571-194.

Yamamoto, T. (1958). Artificial induction of functional sex-reversal in genotypic females of the Medaka (Oryzias latipes). Journal of Experimental Zoology, 137, 227-263.

Yamamoto, T. (1959b). The effects of estrone dosage level upon the percentage of sex-reversals in genetic male (XY) of the medaka (Oryzias latipes). Journal of Experimental Zoology, 141, 133-154.

Yamamoto, T. (1969). Sex differentiation. In W. S., Hoar, \& D.J. Randall, (Eds.), Fish Physiology (pp. 117- 175). NY: Academic Press.

Yamamoto, T., \& Kajishima, T. (1968). Sex hormone induction of sex reversal in the goldfish and evidence for male heterogamity. Journal of Experimental Zoology, 168, 215-222.

Yamamoto, T., \& Matsuda, N. (1963). Effects of estradiol, stilbestrol and some alkyl-carbonyl androstanes upon sex differentiation in the medaka, Oyzias latipes. General and comparative endocrinology, 3, 101-110.

Yamamoto, T. A. (1959a). Further study of induction of functional sex reversal in genotypic males of the medaka (Oryzias latipes) and progenies of sex reversals. Genetics, 44, 739-757.

Yamazaki, F. (1976). Application of hormone in fish culture. Journal of the Fisheries Research Board of Canada, 33, 948-958.

\section{Publisher's Note}

Springer Nature remains neutral with regard to jurisdictional claims in published maps and institutional affiliations.

\section{Submit your manuscript to a SpringerOpen ${ }^{\circ}$ journal and benefit from:}

- Convenient online submission

- Rigorous peer review

- Open access: articles freely available online

High visibility within the field

- Retaining the copyright to your article

Submit your next manuscript at $\boldsymbol{\nabla}$ springeropen.com 